\title{
INTERFERENSI BAHASA INDONESIA SEBAGAI BAGIAN DARI RUMPUN BAHASA AUSTRONESIA
}

\section{Indonesian Interference as Parth of the Austronesian Language Family}

\author{
Rani Siti Fitriani, Riva Nabila \\ Magister Pendidikan Bahasa Indonesia Pascasarjana Universitas Pasundan \\ Jalan Sumatera No. 41 Kota Bandung 40117 \\ E-mail: ranisitifitriani19@gmail.com
}

\begin{abstract}
The changes of the sosio cultural in society have brought changes to teh develpoment of the Indonesian languange as part of the Ausronesian langunage family. Indonesian languange intreference is a form of Autronesian languange development that occurs in bilingua; or multilingual apeakers in heterogeneous societies. Interfernce is influenced by three factors, namely, source languange, recipient languange, andimportation. This study is to descirbe Indonesia languange interfernce in terms of languange symptoms. The theory used in this research is Weinreich's (1968) interference and Mahayana's (2010) theory of Malayroots. The linguistic data used as the source of this study were obtained by collecting data in the form of interviews and listening. This research method using descriptive method. The result of this study indicate that the interference in Indonesia as part of the Austroneisan langunage family consists of word formations such as removing phonemes and adding phonemes.
\end{abstract}

Keyword: interference, Indonesia language, Austronesian languange family

\begin{abstract}
AbSTRAK
Perubahan sosial budaya di masyarakat membawa perubahan pada perkembangan bahasa Indonesia sebagai bagian dari rumpun bahasa Austronesia. Interferensi bahasa Indonesia merupakan salah satu bentuk dari perkembangan bahasa Austronesia yang terjadi pada penutur bilingual atau multilingual dalam masyarakat heterogen. Interferensi dipengaruhi oleh tiga usur yaitu, bahasa sumber, bahasa resipien, dan importasi. Penelitian ini untuk mendeskripsikan interferensi bahasa Indonesia ditinjau dari gejala bahasa. Teori yang digunakan dalam penelitian ini adalah interferensi Weinreich (1968) dan teori tentang akar melayu Mahayana (2010). Data kebahasaan yang dijadikan sumber penelitian ini diperoleh dengan teknik pengumpulan data berupa, wawancara, simak, Metode penelitian ini menggunakan metode deskriptif. Hasil penelitian ini menunjukkan bahwa interferensi dalam bahasa Indoenesia sebagai bagian dari rumpun bahasa Austronesia terdiri dari bentukan kata seperti penghilangan fonem dan penambahan fonem.
\end{abstract}

Kata kunci: interferensi, bahasa Indonesia, rumpun bahasa Austronesia

\section{PENDAHULUAN}

$\mathrm{B}^{\mathrm{a}}$ ahasa Indonesia merupakan bahasa persatuan sebagai alat pemersatu rakyat Indonesia yang memiliki latar beragam suku, budaya, dan bahasa daerah. Penutur berbahasa Jawa sebenarnya memiliki kuntitas yang paling banyak di Indonesia karena pulau Jawa merupakan pulau yang paling banyak penduduknya. Oleh karena itu, penutur bahasa Jawa paling banyak dibandingkan penutur bahasa daerah lainnya 
yang tersebar di beberapa daerah seperti Jawa Tengah, Jawa Timur, Yogyakarta, Cirebon, dan daerah lainnya. Oleh karena itu, tak dipungkiri apabila pada awalnya bahasa Jawa sempat diajukan sebagai cikal bakal bahasa nasional. Namun akhirnya diputuskan bahwa bahasa Melayu yang dijadikan sebagai bahasa nasional karena bahasa Melayu tidak memiliki tingkat tutur seperti bahasa Jawa atau bahasa daerah lainnya.

Bahasa Indonesia berasal dari bahasa Melayu yang tumbuh berkembang sejak abad ke-7 dan dipergunakan sebagai bahasa perhubungan 'lingua franca' diIndonesia dan Asia Tenggara. Bahasa Melayu merupakan bahsa Melayu Polnesia dalam rumun bahasa Austronesia. Jumlah penutur bahasa Melayu sekitar 250 juta orang. Bahasa Melayu menjadi bahasa dengan jumlah penutur terbanyak keempat di dunia. Bahasa Melayu menjadi bahasa resmi di Brunai, Malaysia, Singapura, dan bahasa kerja di Timor Leste, di Afrika Selatna, Sri Lanka, Thailand Selatan, Filipin Selatan, Myanmar Selatan, sebagian kecil Kamboja Papua Nugini, juga di kepualauan di Australia yaitu Pulau Natal dan Pulau Cocos. Bahasa Melayu termasuk dalam bahasa-bahasa Melayu Polinesia rumpun bahasa Austronesia. Linguistik merupakan ilmu yang memelajari bahasa dan seluk beluk bahasa.

Rumpun bahasa Melayu dari tinjauan linguistik memiliki 45 ragam bahasa yaitu,

1) Bahasa Melayu Pasar yang terdiri dari 11 bahasa.

2) Bahasa Melayu Indonesia Timur;

- Bahasa Melayu Ambon

- Bahasa Melayu Banda

- Bahasa Melayu Kupang

- Bahasa Melayu Manado
- Bahasa Melayu Maluku Utara

- Bahasa Melayu Papua

2) Bahasa Betawi;

3) Bahasa Melayu Bali;

4) Bahasa Melayu Bima (Mbojo);

5) Bahasa Melayu Cocos,

6) Bahasa Melayu Larantuka;

7) Bahasa Melayu Makassar;

8) Bahasa Bangka;

9) Bahasa Belitung;

10) Bahasa Banjar;

11) Bahasa Melayu Brunei;

12) Bahasa Duano;

13) Bahasa Indonesia;

14) Bahasa Jakun;

15) Bahasa Kaur;

16) Bahasa Kerinci;

17) Bahasa Loncong;

18) Bahasa Lubu;

19) Bahasa Malaysia;

20) Bahasa Melayu Bacan;

21) Bahasa Melayu Berau;

22) Bahasa Melayu Tengah;

23) Bahasa Melayu Kedah;

24) Bahasa Melayu Kelantan;

25) Bahasa Melayu Kota Bangun Kutai;

26) Bahasa Melayu Pahang;

27) Bahasa Melayu Pattani;

28) Bahasa Melayu Sabah;

29) Bahasa Melayu Terengganu;

30) Bahasa Dayak Melayik;

31) Bahasa Minangkabau;

32) Bahasa Musi;

33) Bahasa Melayu Negeri Sembilan; 
34) Bahasa Orang Kanaq;

35) Bahasa Melayu Timor Leste;

36) Bahasa Orang Seletar;

37) Bahasa Pekal;

38) Bahasa Temuan;

39) Bahasa Urak Lawoi'; dan

40) Bahasa Yawi.

Bahasa Melayu termasuk dalam bahasabahasa Melayu Polinesia rumpun bahasa Austronesia. Jumlah penutur bahasa Melayu di dunia diperkirakan mencapai 250 juta orang dan menempati urutan keempat jumlah penutur terpenting bahasa-bahasa di dunia. Rumpun bahasa Austronesia. Menurut Peter Bellwood dosen Arkeologi di School of Ascheology and Antropology Australian National University dalam "The Austronesians in History: Common Origins and Diverse Transformations: di The Austronesians, Historical and Comparative Perspective," itu berkisar dari bahasa dengan puluhan juta penutur seperti Melayu, Jawa, dan Tagalog.

Bahasa merupakan alat komunikasi yang tumbuh dan berkembang dengan dipengaruhi latar sosial budaya dan ilmu pengetahuan teknologi di masyarakat. Bahasa Austronesia, ragam bahasa Austronesia, bahasa Melayu, bahasa Indonesia, dan bahasa daerah lainnya memiliki karakter yang mungkin ada persamaan atau perbedaan. Bahasa merupakan suatu sistem.

Tabel 1. Karakter Sistem Bahasa

\section{Bahasa itu adalah sistem}

Bahasa itu berwujud lambang

Bahasa itu berupa bunyi

Bahasa itu bersifat arbiter

Bahasa itu bermakna

Bahasa itu konvensional
Bahasa itu bersifat unik

Bahasa itu bersifat universal

Bahasa itu bersifat produktif

Bahasa itu bersifat dinamis

Bahasa itu sebagai alat interaksi sosial

Bahasa itu merupakan identitas penuturnya

Bahasa sebagai alat komunikasi

Bahasa sebagai alat untuk mengungkapkan ide, dan gagasan, perasaan.

Bahasa Indonesia sebagai bagian dari bahasa rumpun Austronesia menjadi alat komunikasi dan perhubungan antarmasyarakat yang heterogen dan dinamis di Indonesia. Oleh karena itu, masyarakat Indonesia banyak yang menggunakan campur kode, bahasa Indonesia dan bahasa daerah dalam komunikasi dan interaksi sosialnya. Bahasa Indonesia sering menjadi bahasa ibu (B1) di daerah perkotaan dan masyarakat heterogen karena memudahkan komunikasi. Namun, bagi masyarakat yang tinggal di daerah, bahasa ibu (B1) yang digunakan dalam komunikasi adalah bahasa daerah masing-masing. Fenomena interferensi bahasa terjadi pada masyarakat heterogen dengan penutur bilingual dan multilingual. Interferensi bahasa adalah gejala 'penyimpangan' bahasa, baik ragam tulis maupun lisan, oleh penutur bilingual atau multilingual yang dipengaruhi oleh pemakaian bahasa ibu (B1), bahasa kedua (B2), dan lebih, akibat campur kode.

Tiga hal yang memengaruhi interferensi bahasa yaitu,

1) bahasa sumber atau bahasa donor yaitu, bahasa yang menyusup unsur-unsurnya atau sistemnya ke bahasa lain; 
2) bahasa penerima atau bahasa resipien yaitu, bahasa yang menerima atau yang disisipi oleh bahasa sumber tadi; dan

3) bahasa yang terserap atau menyusup (importasi) atau unsur serapan.

\section{PEMBAHASAN}

Fenomena interferensi bahasa saat ini banyak ditemukan baik dalam bentuk ragam lisan maupun ragam tulisan baik di media sosial, buku fiksi, dan sebagainya. Penulis mengumpulkan data lisan dan data tulisan dari media sosial wa dan fb.

\section{Interferensi penambahan fonem}

- Penggunaan huruf konsonan /s/ pada kata teman dalam bahasa Indonesia yang berubah menjadi temans untuk menunjukkan jamak.

"Temans nanti jangan lupa rapat pukul 13.00 , ya!"

Bentuk jamak dalam bahasa Indonesia terdiri dari reduplikasi (perulangan), kata bilangan (numeralia), atau bentuk kata yang menyatakan jamak. Misalnya, kata dasar kertas bentuk jamaknya terdiri dari kertaskertas, tiga kertas, dan banyak kertas. Berbeda dengan bentuk jamak dalam bahasa Inggris ditandai dengan penambahan akhiran 's', 'es', dan 'i'. Misalnya, book (tunggal) menjadi books (jamak); glass (tunggal) menjadi glasses (jamak); dan stimulus (tunggal) menjadi stimuli (jamak). Contoh kasus interferensi bahasa pada kalimat berikut.

- "Temans nanti jangan lupa rapat puku 13.00, ya!"

Kata jamak teman dalam bahasa Indonesia tidak ditulis teman-teman, dua teman, atau banyak teman tetapi ditulis temans. Kaidah kata jamak akhiran ' $s$ ' lazim digunakan untuk penulisan kata jamak dalam bahasa Inggris friend (tunggal) dan friends (jamak).

\section{Penambahan Fonem}

Interferensi efentesis yakni penambahan fonem ditemukan dalam penanda interjeksi ah menjadi ach. Penambahan fonem tersebut untuk membuat tuturan lebih akrab. Dalam perkembangan bahasa Indonesia muncul ragam bahasa gaul yang dipengaruhi oleh bahasa asing dan bahasa daerah. Begitupun dengan interferensi penanda interjeksi ah menjadi ach dipengaruhi oleh bahasa gaul yang memang menjadi bahasa yang sering digunakan oleh masyarakat dalam ragam tulisan.

\section{Interferensi penambahan fonem}

- Penggunaan huruf konsonan /c/ pada penanda interjeksi ah menjadi ach dalam bahasa Indonesia.

“Mau ikutan ach ... Dr dulu suka d foto dgn tangan hrs seperti merogoh saku ...."

Bentuk interferensi bahasa lainnya adalah penambahan fonem di tengah, di akhir kata, dan di awal kata. Misalnya, kata siap menjadi siyap merupakan kasus efentesis yakni interferensi bahasa berupa penambahan fonem di tengah kata dan palatisasi yakni penambahan fonem palatal ' $y$ ' saat dilafalkan pada kata siap menjadi siyap. Tujuan penambahan fonem ' $y$ ' di tengah kata siap untuk mempertegas juga menciptakan ragam kata baru yakni ragam bahasa Indonesia bahasa gaul.

\section{Interferensi penambahan fonem}

- Penggunaan huruf konsonan /c/ pada penanda interjeksi ah menjadi ach dalam bahasa Indonesia.

"Siyap ... saya ikut saja, Bu." 


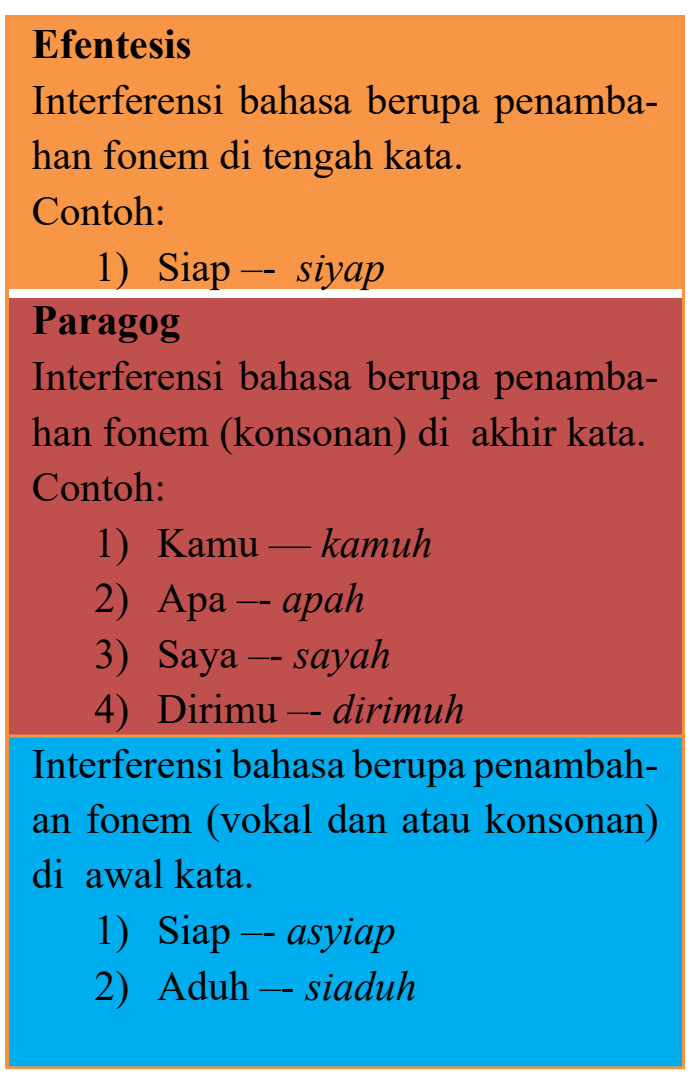

Perubahan kata kamu menjadi kamuh, apa menjadi apah, saya menjadi sayah, dan dirimu menjadi dirimuh. dan sebagainya merupakan kasus interferensi paragog yakni penambahan fonem (konsonan) di akhir kata. Tujuan penambahan fonen (konsonan) di akhir kata untuk menciptakan ragam bahasa Indonesia bahasa gaul dengan kata baru dalam ragam santai juga dipengaruhi oleh bahasa daerah yakni bahasa Sunda. Dalam tuturan bahasa Sunda kerapkali digunakan penanda interjeksi atau penanda fatis mah. Misalnya, "Saya mah mau ikut." Tujuan pemakaian mah pada kalimat tersebut untuk mempertegas tuturan pernyataan dan untuk menciptakan hubungan yang akrab antara penutur dan mitra tutur. Interferensi bahasa berupa penambahan fonem (vokal dan atau konsonan) di awal kata seperti siap menjadi asyiap dan aduh menjadi siaduh sebagai bentuk ragam bahasa yang bertujuan untuk membuat komunikasi lebih santai dan akrab.

\section{Interferensi penambahan fonem}

- Penggunaan huruf konsonan /s/ pada penanda fatis dalam bahasa Indonesia.
- "Idola ayem ... Tonton dongs ... walau sakerejep.."

Penambahan fonen pada penanda interjeksi dong menjadi dongs merupakan kasus interferensi bahasa paragog. Penanda interjeksi dong digunakan untuk tujuan menciptakan hubungan yang akrab. Begitupun penggunaan penanda interjeksi dongs pada tuturan "Idola ayem ... Tonton dongs ... walau sakerejep.." bertujuan untuk menciptakan hubungan yang akrab dan huruf konsonan $s$ digunakan sebagai penekanan pada penanda interjeksi dong. Berdasarkan hasil wawancara dengan responden, dijelaskan bahwa penutur menggunakan konsonan $s$ pada kata dong bertujuan untuk penekanan dan permohonan atau permintaan kepada mitra tutur agar bersedia melakukan apa yang diminta oleh penutur. Tuturan di atas mendeskripsikan fenomena campur kode penutur bilingual. Penutur menggunakan campuran bahasa Indonesia dan ragam bahasa Betawi juga bahasa Sunda. Dalam masyarakat heterogen menjadi fenomena ynag lumrah terkait penutur bilingual dan multilingual. Bahasa Interferensi bahasa Indonesia dalam ragam bahasa lisan kerapkali terjadi karena dilatarbelakangi karena bahasa ragam lisan bersifat spontan dan improvisasi yang dilatarbelakangi oleh konteks pemakaiannya. Interferensi bahasa Indonesia dalam ragam tulisan dilakukan oleh penutur-penulis bertujuan untuk menciptakan hubungan yang akrab dengan mitra tutur-pembaca. 


\section{Penghilangan Fonem}

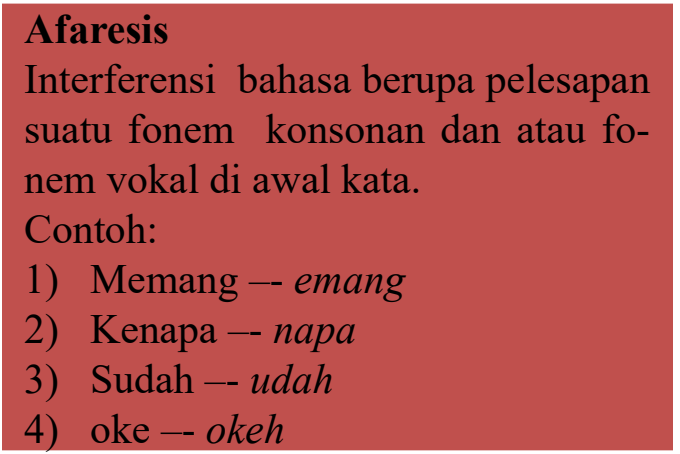

\section{Sinkope}

Interferensi bahasa berupa pelesapan fonem di tengah kata.

Contoh:
1) Tahadi -- tadi
2) Sahaja -- saja
3) Sekarang -- skarang

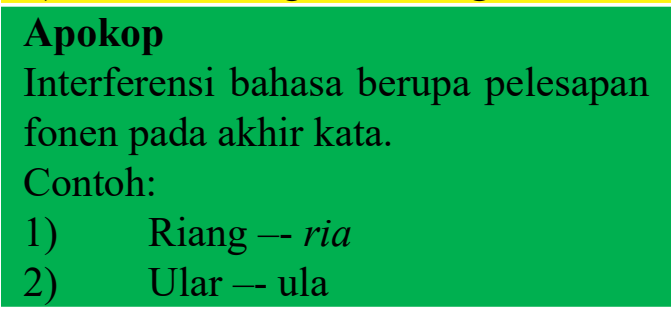

Data kasus interferensi sinkope yakni pelesapan fonem di tengah kata merupakan hilangnya vokal suara dalam kasual pengucapan seperti pada kata sekarang menjadi skarang.

\section{Interferensi penambahan fonem}

- Penggunaan huruf konsonan /s/ pada penanda fatis dalam bahasa Indonesia.

\section{- "Idola ayem ... Tonton dongs ... walau sakerejep..."}

Sinkope dideskripsikan juga dengan penghapusan atau penghilangan fonem huruf vokal atau penghilangan huruf vokal konsonan 'er' dan diganti dengan apostrof dalam ragam tulisan. Sinkope merupakan suatu gejala bahasa berupa penghilangan bunyi pada posisi tengah tanpa mengubah arti kata itu (Kridalaksana, 2001: 198). Misalnya, tahadi menjadi tadi dan sekarang menajdi skarang. Dalam sejarah perkembangan suatu bahasa, nilai fonetik suatu segmen dapat berubah melalui banyak cara. Ada yang terjadi melalui pelesapan bunyi dan juga yang disebabkan oleh proses penyisipan/penambahan bunyi (Mahsun, 2007: 26).

Jenis pelesapan bunyi yang telah dikenal, yaitu aferesis (pelesapan bunyi pada poisi awal), sinkope (penghilangan bunyi pada poisi tengah), dan apokope (penghilangan bunyi pada posisi akhir). Ada banyak hal yang menyebabkan terjadinya pelesapan bunyi. Selain karena keinginan untuk menghemat tenaga dan mempermudah tuturan, menurut Verhaar (1993:47) hal ini juga disebabkan oleh dalam parole suatu bahasa, penutur cenderung lalai dalam artikulasi yang sulit. Mengenai faktor-faktor yang menyebabkan terjadinya pelesapan bunyi ini akan dibahas pada bagian tersendiri.

Kasus interferensi apokop merupakan gejala bahasa berupa penghilangan bunyi bahasa pada posisi akhir tanpa mengubah arti. Misalnya, riang menjadi ria dan ular menjadi ula. Faktor linguistik penghilangan bunyi terjadi karena pengaruh parole. Penutur bahasa cenderung mengilangkan fonem di akhir kata karena tujuan efektif tetapi tidak merubah makna kata tersebut.

\section{SIMPULAN}

Interferensi dalam bahasa Indonesia sebagai rumpun bahasa Austronesia menjadi fenomena yang sering terjadi karena dipengaruhi oleh beberapa faktor, yaitu (1) perubahan sosial budaya di masyarakat yang heterogen; (2) penutur bilingual dan multilingual; (3) pengaruh bahasa asing dan bahasa daerah; (4) ragam bahasa Indonesia, 
bahasa gaul; dan (5) strategi pragmatik dalam menyampaikan tujuan penutur kepada mitra tutur; dan (6) menciptakan hubungan yang akrab antara penutur dan mitra tutur. Bahasa Indonesia sebagai rumpuh bahasa Melayu Austronesia akan terus tumbuh, berkembang, dan mengalami interferensi bahasa karena bahasa sebagai alat komunikasi yang memiliki karakter arbiter, unik, produktif, dan dinamis.

\section{DAFTAR PUSTAKA}

Sumbawa Arikunto, Suharsimi. 2002. Prosedur Penelitian: Suatu Pendekatan Praktek. Jakarta: Rineka Cipta.

Kridalaksan, Harimurti. 2001. Kamus Linguistik. Jakarta:Gramedia Pustaka Utama.

Mahsun. 1995. Dialektologi Diakronis: Sebuah Pengantar.Yogyakarta: Gadjah Mada University Press.

Mahsun. 2007. Linguistik Historis Komparatif. Yogyakarta: Gama Media.
Mahsun. 2007.Metode Penelitian Bahasa; Tahapan Strategi, Metode, dan Tekniknya. Jakarta: Raja Grafindo Persada.

Notosudirjo, Suwardi. 1991. Kosakata Istilah Linguistika untuk SMTA. Yogyakarta: Kanisius. Nurhasanah. 2004. "Kalimat Negatif dalam Bahasa Sumbawa Dialek Sumbawa Basar". Mataram: Universitas Mataram.

Saussure, de Ferdinand. 1993. Pengantar Linguistik Umum. Yogyakarta: Gadjah Mada University Press.

Verhaar, JWM. 1993. Pengantar Linguistik. Yogyakarta:Gadjah Mada Universuty Press.

Verhaar, JWM.. 1996. Asas-Asas Linguistik Umum. Yogyakarta: Gadjah Mada University Press.

\section{HASIL DISKUSI}

Tidak ada pertanyaan 
PROSIDING — Seminar Nasional Arkeologi 2019 